\title{
Evaluation of the effectiveness of the Ministry of Food programme on self-reported food consumption and confidence with cooking
}

\author{
Jayne Hutchinson ${ }^{1}$, Jennifer F. Watt ${ }^{1}$, Emma K. Strachan ${ }^{2}$ and Janet. E. Cade ${ }^{1}$ \\ ${ }^{1}$ Nutritional Epidemiology Group, School of Food Science and Nutrition, University of Leeds, Willow Terrace, \\ Road, Leeds LS2 9JT, UK. and ${ }^{2}$ The Office of the Director of Public Health, Tech North, 9 Harrogate Road, Leeds, \\ LS7 $3 N B$
}

Lack of cooking skills have been associated with poor diet, and increased consumption of highly processed and energy dense convenience food of reduced nutritional quality ${ }^{(1,2)}$. Furthermore, households of lower-income often have poor diets and are at greater risks of diet-related diseases ${ }^{(3,4)}$. Jamie Oliver's Ministry of Food $(\mathrm{MoF})$ campaign aims to reduce diet-related inequalities by teaching individuals how to prepare quick, healthy and low cost home cooked family meals, using fresh ingredients. The main objective of this study was to evaluate the impact of the MoF cooking course in individuals who attended the Leeds Kirkgate Market centre from 2010 to 2014.

The MoF 8 week cooking course was evaluated both quantitatively and qualitatively. In this pre-post study, quantitative outcomes were measured prior to and immediately after the course, and at a 6 month follow-up. Self-administered questionnaires were used to record the number of portions of fruit and vegetables $(\mathrm{F} \& \mathrm{~V})$ consumed per day, number of snacks consumed per day, and participants' cooking confidence levels (highest score of 5). 795 adults ( $43 \%$ male) were evaluated; 462 completed questionnaires at all three time points. More than double the national average of deprived individuals were recruited. Qualitative evaluations of 40 individuals were undertaken using structured telephone interviews.

\begin{tabular}{|c|c|c|c|c|c|c|c|}
\hline \multirow[t]{2}{*}{ Mean intake/scores } & & \multicolumn{2}{|c|}{ Before course } & \multicolumn{2}{|c|}{ After course } & \multicolumn{2}{|c|}{6 months after } \\
\hline & & mean & $(95 \% \mathrm{CI})$ & Mean & $(95 \% \mathrm{CI})$ & mean & $(95 \% \mathrm{CI})$ \\
\hline \multirow[t]{2}{*}{ Portions of Fruit \& Vegetables/ day } & $\mathrm{N}=795^{\mathrm{a}}$ & $2 \cdot 7$ & $(2 \cdot 6,2 \cdot 8)$ & $3 \cdot 4 *$ & $(3 \cdot 3,3 \cdot 5)$ & - & - \\
\hline & $\mathrm{N}=462^{\mathrm{b}}$ & $2 \cdot 7$ & $(2 \cdot 5,2 \cdot 8)$ & $3 \cdot 4^{*}$ & $(3 \cdot 3,3 \cdot 5)$ & $4 \cdot 1^{*}$ & $(4 \cdot 0,4 \cdot 3)$ \\
\hline \multirow[t]{2}{*}{ Frequency of Snacks/ day } & $\mathrm{N}=795^{\mathrm{a}}$ & $2 \cdot 0$ & $(1 \cdot 9,2 \cdot 1)$ & $1.7 *$ & $(1.6,1.8)$ & - & - \\
\hline & $\mathrm{N}=462^{\mathrm{b}}$ & $2 \cdot 0$ & $(1 \cdot 9,2 \cdot 1)$ & $1 \cdot 6^{*}$ & $(1.5,1 \cdot 8)$ & $1 \cdot 1^{*}$ & $(1 \cdot 0,1 \cdot 2)$ \\
\hline \multirow[t]{2}{*}{ Cooking confidence Score } & $\mathrm{N}=795^{\mathrm{a}}$ & $2 \cdot 7$ & $(2 \cdot 6,2 \cdot 8)$ & $4 \cdot 1^{*}$ & $(4 \cdot 0,4 \cdot 2)$ & - & - \\
\hline & $\mathrm{N}=462^{\mathrm{b}}$ & $2 \cdot 7$ & $(2 \cdot 6,2 \cdot 8)$ & $4 \cdot 1^{*}$ & $(4 \cdot 1,4 \cdot 2)$ & $4 \cdot 4^{*}$ & $(4 \cdot 4,4 \cdot 5)$ \\
\hline
\end{tabular}

participants who completed the course and the questionnaires before and immediately after the course, ${ }^{b}$ participants who completed questionnaires at 3 times points. * Differences in intake and scores between all collection points were all statically significant at $\mathrm{p}<0 \cdot 001$.

Six months after the course self-reported F\&V intake had significantly increased from the start of the course by 1.5 (95 $\%$ CI 1.3 , $1.6, \mathrm{p}<0.001)$ portions per day, the number of snacks reported significantly decreased over the same period by $-0 \cdot 9(\mathrm{CI}:-1 \cdot 0,-0 \cdot 8$, $\mathrm{p}<0.001)$ snacks per day, and cooking confidence increased over the same period by $1.7(95 \%$ CI $1.6,1.9, p<0.001)$. Age and disability, but not deprivation or ethnicity were associated with changes in self-reported $\mathrm{F} \& \mathrm{~V}$ intake and cooking confidence scores at six months; and gender with the latter outcome. Qualitative results supported quantitative findings and revealed specific beneficial gains in cooking skill/preparation, nutritional awareness, food purchasing and other social benefits. In conclusions: MoF community based cooking interventions can have significant positive effects on dietary behaviour, food choice and cooking confidence.

1 Brunner TA, van der Horst K, Siegrist M (2010) Appetite 55, 498-506.

2. Hartmann C, Dohle S, Siegrist M (2013) Appetite 65, 125-131.

3. James WP, Nelson M, Ralph A et al. (1997) BMJ 314, 1545.

4. Darmon N, Drewnowski A (2015) Nutr Rev 73, 643-660. 